\title{
Capsule Commentary on Shahinian et al.: Patterns of Bone Mineral Density Testing in Men Receiving Androgen Deprivation for Prostate Cancer
}

\author{
David F. Penson, $\mathrm{MD}, \mathrm{MPH}^{1,2}$ \\ ${ }^{1}$ Urologic Oncology, Vanderbilt University Medical Center, Nashville, TN, USA; ${ }^{2}$ VA Tennessee Valley GRECC, Nashville, TN, USA.
}

J Gen Intern Med 28(11):1494

DOI: $10.1007 / \mathrm{s} 11606-013-2513-2$

(c) Society of General Internal Medicine 2013

$\mathrm{T}$ his analysis of SEER-Medicare data by Shahinian and Kuo compared bone mineral density (BMD) testing in prostate cancer survivors on androgen deprivation therapy (ADT) to prostate cancer survivors who were not receiving ADT. ${ }^{1} \mathrm{BMD}$ testing in the men on ADT increased from less than 1\% in 1996 to $11.5 \%$ in 2008 . While BMD testing increased in the prostate cancer survivors not on ADT, it occurred at a much lower rate, increasing from less than $1 \%$ to $4.4 \%$. This increase in BMD testing is not surprising and is clinically appropriate given that ADT use is associated with an increased risk of osteoporosis and fractures. The authors also show that patients who were cared for by a urologist alone were significantly less likely to undergo BMD testing than those cared for by both a urologist and a primary care physician (PCP). Given what we know about the bony side effects of ADT, why isn't BMD testing more common?

I believe that the answer lies not in the specialty of the treating physician but in the clinical uncertainty of what to do with the results of BMD testing when ordered. Obviously, if the test finds that the patient is osteoporotic, some type of treatment should be initiated, but should this be an oral alendronate, intravenous zoledronic acid or subcutaneous denosumab, all of which have been shown to be effective in preventing further bone loss? $?^{2-4}$ Furthermore, if BMD testing shows osteopenia or is normal, should one of these agents be used for prevention? The National Comprehensive Cancer Network (NCCN) guidelines on the treatment of prostate cancer suggest initiating treatment in patients at certain increased levels of fracture risk, based upon the FRAX nomogram from the World Health Organization. ${ }^{5}$
The guidelines, however, do not provide guidance on the frequency of BMD testing and are based primarily on expert opinion. Acknowledging these limitations, these guidelines still provide useful information for clinicians, and, as such, urologists and PCPs need to be more aware of bone health in prostate cancer survivors on ADT and perform BMD testing more often.

Conflict of Interest: The author declares he does not have a conflicts of interest.

Corresponding Author: David F. Penson, MD, MPH; Hamilton and Howd Chair in Urologic Oncology, Vanderbilt University Medical Center, 2525 West End Avenue, Suite 1200, Nashville, TN 37203-1738, USA (e-mail: David.penson@vanderbilt.edu).

\section{REFERENCES}

1. Shahinian VB, Kuo Y-F. Patterns of bone mineral density testing in men receiving androgen deprivation for prostate cancer. J Gen Intern Med. doi: 10.1007/s11606-013-2477.2.

2. Klotz LH, McNeill IY, Kebabdjian M, Zhang L, Chin JL, Canadian Urology Research Consortium. A phase 3, double-blind, randomised, parallelgroup, placebo-controlled study of oral weekly alendronate for the prevention of androgen deprivation bone loss in nonmetastatic prostate cancer: the cancer and osteoporosis research with alendronate and leuprolide (CORAL) study. Eur Urol. 2013;63(5):927-935. doi:10.1016/j.eururo.2012.09.007.

3. Saad F, Gleason DM, Murray R, et al. A randomized, placebo-controlled trial of zoledronic acid in patients with hormone-refractory metastatic prostate carcinoma. J Natl Cancer Inst. 2002;94(19):1458-1468.

4. Smith MR, Egerdie B, Hernández Toriz N, et al. Denosumab in men receiving androgen-deprivation therapy for prostate cancer. N Engl J Med. 2009;361(8):745-755. doi:10.1056/NEJMoa0809003.

5. NCCN Clinical Practice Guidelines in Oncology: Prostate Cancer. www.nccn.org. Available at: http://www.nccn.org/professionals/physician_gls/pdf/ prostate.pdf. Accessed May 19, 2013. 